\title{
Reproductive Care of Childhood and Adolescent Cancer Survivors: A 12-Year Evaluation
}

\author{
Antoinette Catherine Anazodo, MBBS, PhD, ${ }^{1-3,{ }^{*}}$ Sumin Choi, MBBS,$^{1, *}$ Christina Signorelli, PhD,,${ }^{1,2}$ \\ Sarah Ellis, BA, ${ }^{1,2}$ Karen Johnston, MNNP, ${ }^{2}$ Claire E. Wakefield, PhD, ${ }^{1,2}$ Rebecca Deans, MBBS, PhD, ${ }^{1,4}$ \\ Kristen A. Neville, MBBS, PhD, ${ }^{1,5}$ and Richard J. Cohn, MBBCh ${ }^{1,2}$
}

\begin{abstract}
Background: Reproductive complications for cancer survivors are identified as one of the top unmet needs in the survivorship period. However, current models of cancer care do not routinely incorporate reproductive follow-up for pediatric or adolescent cancer patients. The Kids Cancer Centre has had a one-stop survivorship clinic that includes the attendance of a gynecologist and fertility specialist for the last 12 years.

Methodology: To inform the future development of our reproductive survivorship care, we reviewed the reproductive care our survivorship clinic has provided over a 12-year period, specifically reviewing the electronic and patient records to collect information on the demographics of the patients who used the service and their gonadotoxic risk and associated fertility treatment, their documented reproductive needs and concerns, and information provided on preventative reproductive advice and screening.

Main Results: Two hundred seventy-eight patients were seen (397 consultations) for advice and management of reproductive issues, including 189 female patients (68.0\%). Survivors' median age at follow-up was 25.0 years (range $=6-50$ ), on average 19.2 years from their primary diagnosis (range $=3-46$ ). The reviewed data had five overarching themes (fertility care, hormone dysfunction, sexual dysfunction, fertility-related psychological distress due to reproductive concerns, and preventative health care), although each theme had a number of components. Patients had on average 2.5 reproductive concerns documented per consultation (range 1-5). The three most commonly documented symptoms or concerns at the initial consultation related to fertility status (43.9\%), endocrine dysfunction (35.3\%), and contraception advice (32.4\%). In patients younger than 25 years, documented discussions were predominately about endocrine dysfunction, fertility status, and contraception, while dominant themes for 26-35-year olds were fertility status, reproductive-related health prevention strategies, contraception, and endocrine dysfunction. Survivors 36-45 years of age prioritized fertility status, pregnancy, and contraception. Fertility preservation (FP) $(p=0.05)$, preventative health strategies $(p=0.001)$, and contraception advice $(p<0.001)$ were more commonly discussed by females than males.

Conclusion: Young cancer survivors have multiple ongoing reproductive concerns that change over time. Assessing survivors' reproductive potential following cancer treatment is important as it gives patients who have not completed their family planning an opportunity to explore a possible window to FP or Assisted Reproductive Treatment. Our data can assist in informing the model of care for a reproductive survivorship clinic.
\end{abstract}

Keywords: cancer survivorship, quality of life, infertility, reproductive concerns, fertility preservation

\footnotetext{
${ }^{1}$ Faculty of Medicine, School of Women and Children's Health, UNSW Australia, Sydney, Australia.

${ }^{2}$ Kids Cancer Centre, Sydney Children's Hospital, Sydney, Australia.

${ }^{3}$ Nelune Comprehensive Cancer Centre, Prince of Wales Hospitals, Sydney, Australia.

${ }^{4}$ Royal Hospital for Women, Sydney, Australia.

${ }^{5}$ Department of Endocrinology, Sydney Children's Hospital, Sydney, Australia.

*The authors consider that the first two authors should be regarded as joint first authors.
} 
Introduction

O NCOFERTILITY DESCRIBES THE reproductive care cancer patients may require at diagnosis, during treatment, and following successful cancer treatment. ${ }^{1}$ The care includes fertility preservation $(\mathrm{FP})^{2}$ and assisted reproduction treatment (ART), ${ }^{2,3}$ management of sexual dysfunction, ${ }^{4}$ management of hormonal deficiency, management of contraception and menstruation, fertility-related health prevention, health screening, and psychosocial support.

Cancer survivors may experience a number of reproductive issues, which include abnormalities in pubertal development, including precocious puberty, delayed or absent pubertal development, ${ }^{5,6}$ menstrual dysfunction, ${ }^{7}$ reproductive endocrine complications $^{8-10}$ sexual dysfunction disorders ${ }^{1,12}$ infertility, ${ }^{1}$ pregnancy, and labor complications. ${ }^{13-16}$ As a result of gonadal dysfunction, they are also at higher risk of cardiovascular, bone, and psychological complications, ${ }^{17-19}$ (which may also impact romantic relationships, sexuality, and quality of life). ${ }^{20,21}$

Successful oncofertility care requires collaboration across disciplines, as well as involvement of a variety of health care professionals (HCPs) who work across pediatric, AYA, and adult care. ${ }^{1}$ Most current models of survivorship care do not systematically incorporate reproductive health care beyond fertility. ${ }^{1,4,22-25}$ Reproductive issues for cancer survivors are repeatedly one of the top five unmet needs in the survivorship period. ${ }^{1,26,27}$

The Kids Cancer Centre at Sydney Children's Hospital has had a well-established survivorship clinic for over 20 years, providing multidisciplinary care to pediatric and AYA cancer survivors. ${ }^{28,29}$ One thousand patients have up-to-date survivorship passports and 300 patients are seen each year for an annual, biannual, or triannual review. In addition, up to $50 \%$ of patients have GP follow-up alone or are lost to follow-up (Wilson CL 2009). A number of HCPs attend the clinic, including pediatric and adult oncologists, pediatric and adult endocrinologists, a clinical nurse consultant, a social worker, a psychologist, a dentist, and a cardiologist. Since 2003, the clinic has also included the attendance of a gynecologist and fertility specialist who now attends 12 clinics a year, although this has increased slowly over time period.

Due to the limited resources, a reproductive specialist initially only provided medical and psychosocial oncofertility care to high-risk male and female survivors and their partners or patients who requested an appointment. Patients were either self-referred or referred by their oncologist, the late-effects nurse consultant, or the Director of the survivorship program. Ongoing clinical review was determined by the clinician reviewing the patient.

Follow-up at the survivorship clinic is according to riskbased guidelines, based on the Children's Oncology Group Survivorship Guidelines, ${ }^{30}$ other published reproductive follow-up guidelines, ${ }^{4,22,23,25,31}$ and FP guidelines. ${ }^{30,32,33}$

To inform the future development of our reproductive survivorship service, we retrospectively reviewed the reproductive care provided over a 12-year period in our survivorship clinic to (1) determine what the medical and psychological reproductive concerns of childhood and adolescent cancer survivors attending our survivorship clinic were, (2) determine the timing of reproductive concerns, and (3) determine if the reproductive concerns change by age and by gender?

\section{Hypothesis}

We hypothesized that survivors have multiple reproductive concerns following cancer treatment and that these concerns will differ for survivors of different ages and gender and change as survivors age.

\section{Materials and Methods}

\section{Eligibility}

Patients younger than 18 years at the time of a cancer diagnosis or who were treated for a non-hematological condition with a bone marrow transplant (BMT), and who received survivorship care between January 2006 and December 2017 within the Late-Effects Clinic at Sydney Children's Hospital, Randwick, were included. All patients attending the survivorship clinic were at least 5 years from their cancer diagnosis or 2 years from undergoing a BMT.

\section{Methods}

Quantitative data were systematically collected from the electronic or paper notes over the 12- year period using a study data collection sheet. The data collected included the following:

(1) Demographic information;

(2) Cancer treatment information, including total dose of each treatment modality where applicable, and dose and field of radiotherapy that had a gonadotoxic risk (neuroendocrine, abdominal, pelvic, gonadal, cranial spinal, and Total Body Irradiation);

(3) Reproductive history and information about FP;

(4) Information on sexual activity, contraception, and sexual dysfunction was collected on all patients older than 16 years;

(5) Other endocrine dysfunction diagnosis and management;

(6) Preventative reproductive advice and treatment, including human papillomavirus (HPV) vaccination for patients older than 12, cervical smears in patients older than 25 years, and advice about breast or testicular self-examination.

Qualitative data, in the form of documented notes on the reproductive concerns of patients who had fertility distress, anxiety, or depression, were extracted by the same two investigators from patients' allied health files, using the study data collection sheet. These notes were collated in Nvivo.

The risk of infertility following treatment for each patient was categorized as no risk, low risk (20\% risk of infertility), intermediate risk (21\%-80\% risk of infertility), and higher risk ( $>81 \%$ risk of infertility), based on studies looking at the reproductive potential of cancer survivors following chemotherapy, radiotherapy, and $\mathrm{BMT}^{34-37}$ and then correlation with patients' actual reproductive function based on available results.

To ensure consistent data interpretation and analysis, the following definitions were followed:

(1) Hypogonadism in children younger than 18 years was defined as failure to progress through puberty without hormone replacement therapy (HRT) or a raised FSH 


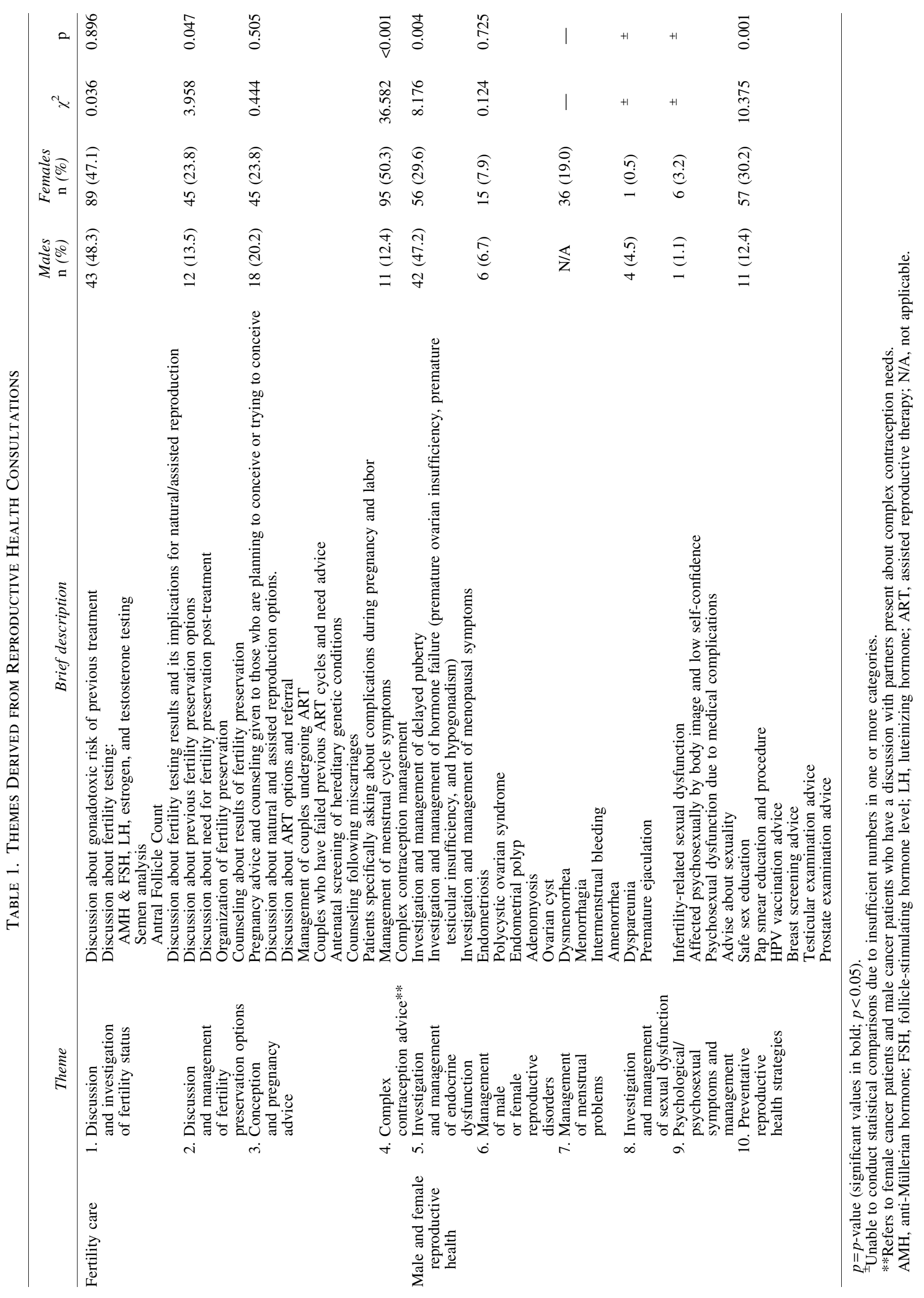


or LH with no clinical signs of puberty in girls older than 12 years and boys older than 13 years. ${ }^{38}$

(2) In patients 18 years and older, who had undergone spontaneous puberty, hypogonadism was defined in women as a history of menstrual irregularity associated with a subnormal estradiol $(<90 \mathrm{pM})$ and in men as a subnormal testosterone level $(<8.4 \mathrm{nM}){ }^{38}$

(3) Premature ovarian insufficiency (POI) was defined as 4 months of amenorrhea or menstrual irregularity due to the loss of ovarian function before 40 years of age. Diagnosis of POI required an FSH $>25$ IU in a woman younger than 40 years.

The data were collected by one researcher (S.C.) and reviewed by a second researcher (A.A.) to ensure data accuracy. Any discrepancy in data coding was resolved by discussions with the senior researchers (R.C./K.N.) to reach consensus.

\section{Ethics}

This study was approved by the South Eastern Sydney Local Health District Human Research Ethics Committee (LNR/16/SCHN/396).

\section{Statistical analysis}

Patient quantitative data were manually entered into Microsoft Excel and SPSS (v.25, 2018). We used descriptive analysis to assess the quantitative data (patient gender, age, relationship status, religion, cancer treatment, reproductive complications, and fertility risk).

Two researchers (S.E. and S.C.) independently read and coded the qualitative data after generating an initial coding tree based on patient's emerging concerns. Discrepancies were resolved with a third researcher (A.A.), resulting in the identification of 10 core themes of patient's reproductive concerns raised in the consultations (listed in Table 1). We used thematic content analysis to analyze the qualitative data. For further analysis, discussion of each of the 10 themes was also recorded in SPSS per patient, specifically to assess group differences and trends in consecutive consultations over time using correlations, paired samples $t$-tests, and one-way and repeated-measures analysis of variance. We conducted multiple regression analyses to explore demographic and clinical factors associated with the total number of documented patient concerns.

\section{Results}

\section{Participant characteristics}

The records of all patients who had a reproductive survivorship consultation between January 2006 and December 2017 were reviewed. This included data from 397 consultations with 278 patients diagnosed at a median age of 6.0 years (range 1-18), who had any reproductive consultation (Table 2). Around $64.7 \%$ were seen by a fertility specialist, $31.3 \%$ were seen by an endocrinologist, and $4.0 \%$ were seen by both. One hundred eighty-nine participants $(68.0 \%)$ were female. Survivors' median age at clinic attendance was 25.0 years $($ range $=6-50)$, and median 19.2 years $($ range $=3-46)$ from their primary diagnosis. Among participants older than 16 years, who were in a relationship based on self-reported registration information, $47.2 \%$ attended the clinic with a partner at their initial visit, which decreased in subsequent visits to $25 \%$ by visit 4 (Table 3 ). Table 2 describes patients' demographic and clinical characteristics at initial referral.

The commonest group of cancer diagnoses in our sample was hematological malignancy $(59.7 \%)$. Most survivors received chemotherapy $(97.1 \%)$, of whom the majority received anthracyclines $\left(78.0 \%\right.$, mean total dose $\left.=239.4 \mathrm{mg} / \mathrm{m}^{2}\right)$. Over half $(55.4 \%)$ also had radiotherapy, of whom $54.0 \%$ received potentially gonadotoxic radiotherapy, which includes $12.0 \%$ who had TBI, $6.8 \%$ pelvic radiotherapy, $3.3 \%$ gonadal radiotherapy, $16.2 \%$ abdominal radiotherapy, and $51.4 \%$, hypothalamic radiotherapy (Table 2). Most survivors were predicted to be at high $(54.2 \%)$ or intermediate $(23.2 \%)$ risk of infertility based on their cancer treatment gonadotoxic risk calculation. $^{34-37}$

\section{Fertility care}

Twenty-five survivors (9\%) underwent FP either before $(12 \%)$ or after cancer $(88 \%)$ treatment, including sperm banking, oocyte cryopreservation, or embryo cryopreservation. Seventy percent of patients who had FP had high gonadotoxicity risk based on treatment. Within the study period, 11 (3.9\%) survivors in this cohort, older than 16 years, conceived naturally. No children were successfully conceived using ART, although the number treated with ART outside the clinic is not known.

\section{Reproductive needs}

Table 1 details the reproductive medical or psychological care needs discussed in the course of the consultation. Twentyseven percent $(n=75)$ of patients had more than one visit to the reproductive survivorship clinic (range 1-5). The concerns were analyzed by "concerns ever raised" across all consultations, that is, topics counted once across all the consults. Survivors typically had between 1 and 2 reproductive-related care needs per consultation and on average, 2.0 reproductive care needs in total across all consultations (range 1-5; Table 3). At their initial visit, $66 \%$ of patients had a discussion about fertility documented. Female survivors had significantly more concerns recorded on average $($ mean $=2.7, \mathrm{SD}=1.9)$ than male survivors across all consultations ( mean $=2.1$, $\mathrm{SD}=1.6, t(276)=-2.655, p=0.008)$.

We found a positive correlation between survivors' age and the total number of topics they raised at consultations $(r=0.141, p=0.019)$. Even after excluding gender-specific topics (e.g., pap smears), females were significantly more likely than males to have a discussion documented about FP options and preventative health strategies, and seek contraception advice, while significantly more males than females had a discussion about the management of endocrine dysfunction (Table 1).

Figure 1 shows the most commonly recorded topics raised by each age group. At initial consultations, the three most common topics raised related to their fertility status (44\%), endocrine dysfunction (35\%), and contraception advice (32\%). Across successive consultations (Fig. 2), these remained the three most commonly documented issues discussed $(48 \%, 35 \%$, and $38 \%$ respectively).

In multiple regression analyses $[F(11,242)=1.980$; Table 2], survivors who were older at diagnosis had greater 
Table 2. Patient Demographic and Clinical Characteristics at Initial Referral and Factors Associated with the Total Number of Survivors' Concerns Raised Across All Consultations

\begin{tabular}{|c|c|c|c|c|c|c|}
\hline \multirow[b]{2}{*}{ Factors } & \multicolumn{3}{|c|}{ Descriptive characteristics } & \multicolumn{3}{|c|}{ Multiple linear regression ${ }^{ \pm}$} \\
\hline & $\mathrm{N}(\%)$ & Median & Range & $\beta$ & $95 \% C I$ & $\mathrm{p}$ \\
\hline $\begin{array}{l}\text { Current age } \\
\text { Vital status }\end{array}$ & $278(100 \%)$ & 25.0 & $6-50$ & & - & \\
\hline $\begin{array}{l}\text { Alive } \\
\text { Deceased }\end{array}$ & $\begin{array}{r}272(98.9 \%) \\
\quad 3(1.1 \%)\end{array}$ & - & - & & - & \\
\hline $\begin{array}{l}\text { Sex } \\
\quad \text { Male } \\
\text { Female }\end{array}$ & $\begin{array}{r}89(32.0 \%) \\
189(68.0 \%)\end{array}$ & - & - & 0.454 & -0.065 to 0.974 & 0.086 \\
\hline $\begin{array}{l}\text { Religion } \\
\text { No religion } \\
\text { Not specified } \\
\text { Christian } \\
\text { Other }\end{array}$ & $\begin{aligned} & 85(31.0 \%) \\
& 43(15.5 \%) \\
& 142(51.1 \%) \\
& 8(2.9 \%)\end{aligned}$ & - & - & 0.090 & -0.383 to 0.563 & 0.708 \\
\hline $\begin{array}{l}\text { Marital status } \\
\text { Single } \\
\text { In a relationship/engaged } \\
\text { Married/de facto } \\
\text { Divorced }\end{array}$ & $\begin{array}{c}202(73.2 \%) \\
17(6.2 \%) \\
55(19.9 \%) \\
2(0.7 \%)\end{array}$ & - & - & 0.409 & & 0.164 \\
\hline $\begin{array}{l}\text { Age at diagnosis } \\
\text { Primary diagnosis } \\
\text { Hematological malignancy } \\
\text { Solid tumor } \\
\text { Benign hematology }\end{array}$ & $\begin{array}{c}- \\
166(59.7 \%) \\
106(38.1 \%) \\
6(2.2 \%)\end{array}$ & 7.1 & $1-18$ & $\begin{array}{r}\mathbf{0 . 0 7 2} \\
-0.137\end{array}$ & $\begin{array}{l}-\mathbf{0 . 1 6 8} \text { to } \mathbf{0 . 9 8 7} \\
-0.746 \text { to } 0.472\end{array}$ & $\begin{array}{l}\mathbf{0 . 0 1 3} \\
0.658\end{array}$ \\
\hline $\begin{array}{l}\text { Cancer treatment }^{\mathrm{a}} \\
\text { Received radiotherapy } \\
\text { Total dose (Gy) } \\
\text { Received chemotherapy }\end{array}$ & $\begin{array}{l}153(55.4 \%) \\
268(97.1 \%)\end{array}$ & 22.5 & $1.2-96.0$ & -0.137 & -0.628 to 0.353 & 0.582 \\
\hline $\begin{array}{l}\text { Anthracyclines }\left(\mathrm{mg} / \mathrm{m}^{2}\right) \\
\text { Alkylating agents }\left(\mathrm{mg} / \mathrm{m}^{2}\right) \\
\text { Platinum agents }\left(\mathrm{mg} / \mathrm{m}^{2}\right) \\
\text { Underwent surgery }\end{array}$ & 85 (30.9\%) & $\begin{array}{c}240.0 \\
3,200.0 \\
1,038.7\end{array}$ & $\begin{array}{r}30.0-572.0 \\
1.0-34,860.0 \\
100.0-10,600.0\end{array}$ & $\begin{array}{l}-0.586 \\
-0.114 \\
-0.155 \\
-0.029\end{array}$ & $\begin{array}{l}-1.219 \text { to } 0.048 \\
-0.787 \text { to } 0.558 \\
-0.839 \text { to } 0.528 \\
-0.63 \text { to } 0.572\end{array}$ & $\begin{array}{l}0.070 \\
0.738 \\
0.655 \\
0.925\end{array}$ \\
\hline Years since diagnosis & - & 19.2 & $3-46$ & 0.001 & -0.032 to 0.034 & 0.958 \\
\hline
\end{tabular}

$\mathrm{CI}=$ Confidence interval; $p=p$-value (significant factors highlighted in bold, $p<0.05$ ).

Data collected at each patient's first consultation; numbers may not add up due to missing information or rounding errors.

${ }^{\text {a} P a t i e n t s ~ m a y ~ h a v e ~ r e c e i v e d ~ m u l t i p l e ~ t r e a t m e n t s . ~}$

${ }^{\mathrm{b}}$ Comprising patients who underwent surgical treatment at high-risk sites, including pelvis, abdomen, cranial, and gonadal.

${ }^{ \pm}$Given high collinearity between survivors' age and the number of years since diagnosis, we only included years since diagnosis in the regression model. For the regression, variables were categorized as follows: religion: $0=$ no religion (including agnostic/atheism) and $1=$ religion identified; marital status: $0=$ single/divorced and $1=$ in a relationship/engaged/married; cancer diagnosis: $1=$ hematological malignancy, $2=$ solid tumor, or $3=$ benign hematology (hematological malignancy $=$ reference group); specific treatments: $0=$ not received and $1=$ received.

needs, as measured by the total number of concerns raised across all consultations $(p=0.003)$. No other clinical (e.g., primary diagnosis and cancer treatment) or demographic factors (e.g., sex and marital status) were associated with the total number of concerns documented.

In consultations, $47.5 \%$ of survivors discussed reproductive status and risk of infertility. Approximately $20.5 \%$ had a consultation about FP, $22.7 \%$ of patients $>18$ years of age sought conception and pregnancy advice, including information about ART, antenatal genetic screening, or the management of pregnancy complications.

\section{Hormonal dysfunction}

Twenty-eight female patients (14.8\%) had a diagnosis of hypogonadism. Six were younger than 18 years and 22 were older than 18 years. Of 175 female survivors 16 years of age and older, 36 (20.6\%) had recorded abnormal uterine bleeding. ${ }^{39}$ Of all female survivors, $59 \%$ had discussions about HRT and 10 underwent HRT treatment.

Twenty-five of the males in this cohort $(28.0 \%)$ had a diagnosis of hypogonadism ( 8 younger than 18 years and 17 older than 18 years). Among 75 males older than 18 years, $15.2 \%$ had a raised FSH and $19.0 \%$ had a raised LH. Around 42.9\% male survivors discussed hormone deficiency and 13 were prescribed testosterone replacement.

\section{Sexual activity and sexual dysfunction}

Among 225 patients older than 16 years, $44 \%$ were documented to be sexually active (68\% female). Of these, $49 \%$ patients or partners were using contraception, primarily oral contraceptive pills $(72 \%)$ and barrier methods of birth control (16\%). 
Table 3. Consultation Characteristics Over Time

\begin{tabular}{|c|c|c|c|c|c|}
\hline & $\begin{array}{l}\text { First visit } \\
\mathrm{N}(\%)\end{array}$ & $\begin{array}{l}\text { Second visit } \\
\mathrm{N}(\%)\end{array}$ & $\begin{array}{l}\text { Third visit } \\
\mathrm{N}(\%)\end{array}$ & $\begin{array}{l}\text { Fourth visit } \\
\text { N (\%) }\end{array}$ & $\begin{array}{c}\text { Fifth visit } \\
\mathrm{N}(\%)\end{array}$ \\
\hline Total number of patients & $278(100 \%)$ & $75(27.0 \%)$ & $34(11.9 \%)$ & $12(4.3 \%)$ & $3(1.1 \%)$ \\
\hline \multicolumn{6}{|l|}{ Age at visit } \\
\hline Mean, SD & $21.2(7.4)$ & $24.5(5.8)$ & $24.9(6.2)$ & $24.7(5.8)$ & $31.3(3.8)$ \\
\hline Range & $6-47$ & $13-39$ & $14-43$ & $14-38$ & $27-34$ \\
\hline \multicolumn{6}{|l|}{ Sex } \\
\hline Male & $91(32.7 \%)$ & $24(32.0 \%)$ & $10(30.3 \%)$ & $2(16.7 \%)$ & $1(33.3 \%)$ \\
\hline Female & $187(67.3 \%)$ & $21(68.0 \%)$ & $23(69.7 \%)$ & $10(83.3 \%)$ & $2(66.7 \%)$ \\
\hline \multicolumn{6}{|l|}{ Consultation type } \\
\hline Gynecology/Fertility & $161(64.7 \%)$ & $64(94.1 \%)$ & $24(72.7 \%)$ & & \\
\hline Endocrinology & $78(31.3 \%)$ & $4(5.9 \%)$ & $5(15.2 \%)$ & - & - \\
\hline Gynecology/Fertility/Endocrinology & $10(4.0 \%)$ & 0 & $1(3.0 \%)$ & & \\
\hline Partner present at consultation & $34 / 72(47.2 \%)$ & $3 / 23(13.0 \%)$ & $4 / 14(28.6 \%)$ & $1 / 4(25.0 \%)$ & $0 / 1(0 \%)$ \\
\hline Discussed fertility & $184(66.2 \%)$ & $50(80.0 \%)$ & $25(75.8 \%)$ & $10(83.3 \%)$ & $3(100.0 \%)$ \\
\hline \multicolumn{6}{|l|}{ Number of topics discussed } \\
\hline Mean, SD & $1.7(0.9)$ & $1.9(0.7)$ & $1.5(0.6)$ & $1.9(0.8)$ & $1.7(0.6)$ \\
\hline Range & $1-5$ & $1-4$ & $1-3$ & $1-3$ & $1-2$ \\
\hline
\end{tabular}

Numbers may not add up due to missing information or rounding errors.

Nine patients older than 16 years had recorded symptoms or signs of sexual dysfunction (e.g., dyspareunia and premature ejaculation). Around $7.9 \%$ of all females, and $6.7 \%$ of all males, had reproductive health problems unrelated to a cancer diagnosis or treatment (endometriosis, polycystic ovarian syndrome, endometrial polyps, adenomyosis, or ovarian cysts in females and testicular torsion, varicocele, epididymitis, hydrocele, or hypospadias in males).

Only $20(7.2 \%)$ survivors had fertility-related psychosocial or psychosexual problems. Psychosocial problems were most commonly recorded for survivors 26-35 years of age (35.0\% of discussions), followed by survivors 13-17 years of age $(30.0 \%)$.

\section{Preventative reproductive health}

Approximately $12.4 \%$ of males and $30.2 \%$ of females older than 16 years sought advice regarding at least one aspect of reproductive health such as pap smears or practicing safe sex. Nineteen female survivors older than 18 years

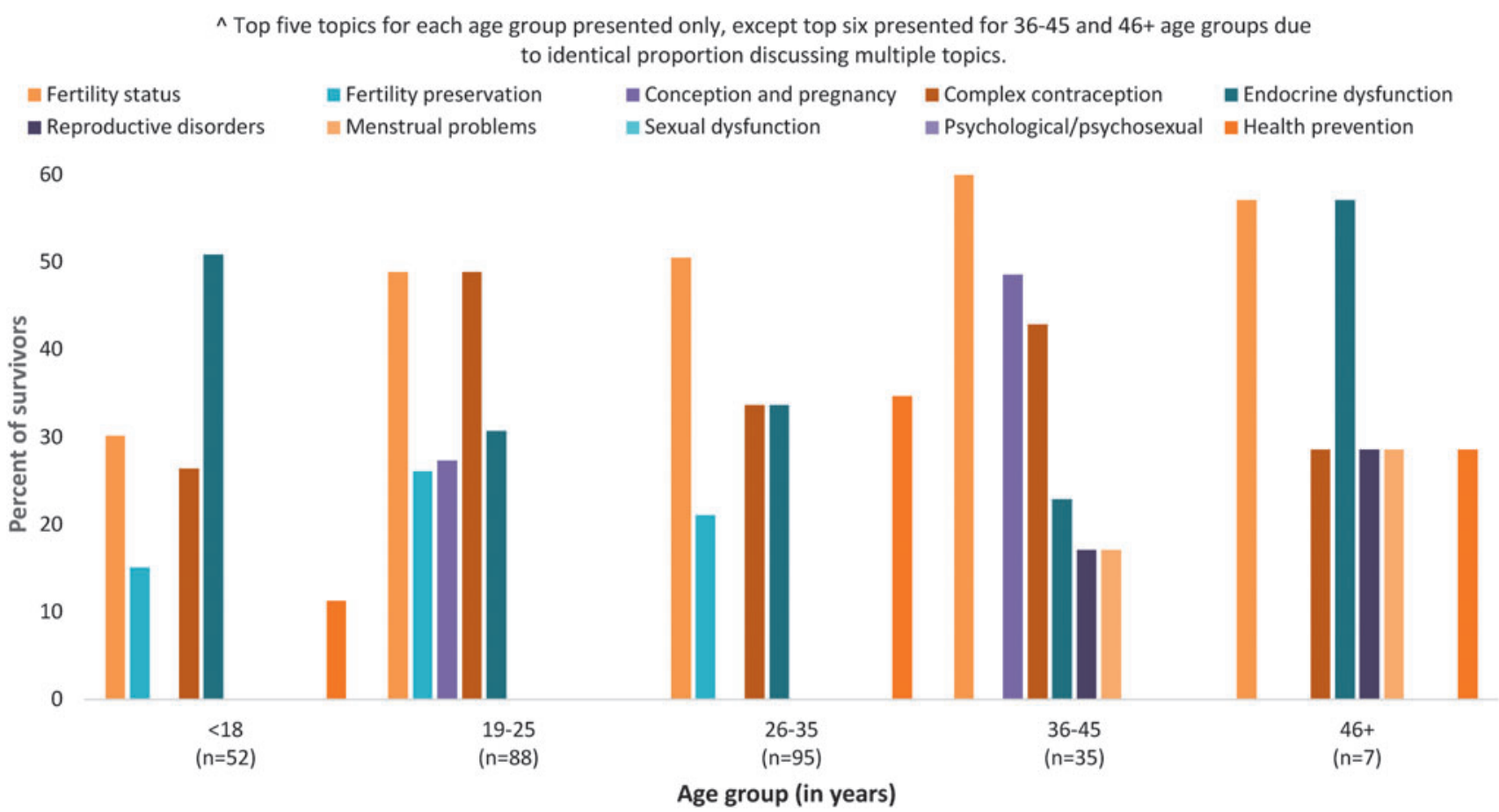

FIG. 1. Top five reproductive topics discussed by each age group. 


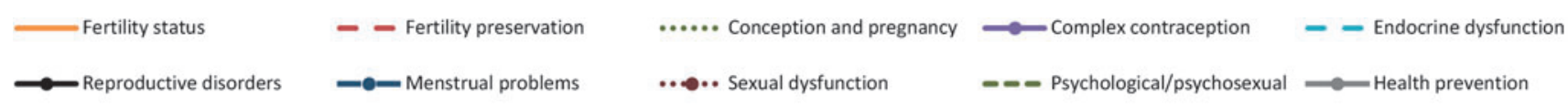

40

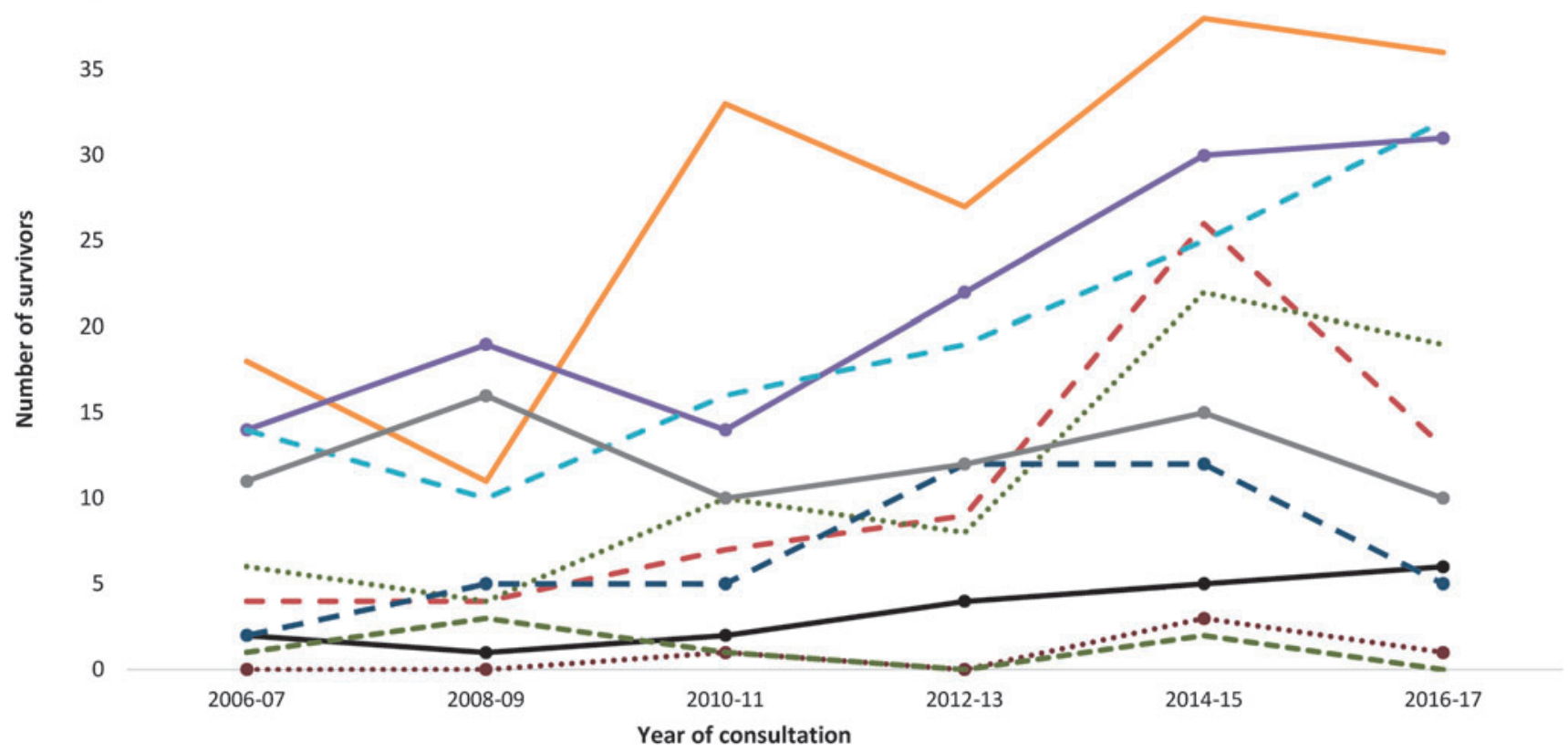

FIG. 2. Trends in reproductive topics raised over time by year of consultation.

$(10.1 \%)$ had pap smears completed at the clinic. Of those who had a pap smear, seven showed an abnormality, including atrophy or cervical intraepithelial neoplasia (CIN; levels 1 and 2). Of eligible survivors (females older than 12 years), $32.0 \%$ were immunized for HPV and a further $11.1 \%$ were advised to receive the vaccination. The HPV immunization status of $49.4 \%$ of eligible female survivors $(n=182)$ was not recorded. Around $24.5 \%$ of all patients/parents also engaged in other preventative health discussions (breast examination, testicular examination, and safe sex education). The Australian vaccination schedule included HPV vaccination for males from 2014 and we did not have any male patient who had documented HPV vaccination.

\section{Psychological and psychosexual impact of reproductive issues}

Qualitative data analysis resulted in three key subcategories of perceived psychological and psychosexual impact of fertility: (1) anxiety/worry, (2) shock, and (3) avoidance. The psychosocial concerns collected are only those patients related to reproductive concerns.

The first theme related to survivors' anxieties or worries around their risk of infertility and its implications. Some survivors reported a negative impact on their self-esteem ranging more broadly: " "...feeling low on body image, selfworth, and identity as a woman" to more specific examples, where survivors expressed concern about factors such as their "penile length and the cosmetic appearance of their testes." Missed opportunities for FP in the past resulted in clinicians noting that some survivors felt angry, for example, "angry at her parents for not preserving the eggs, as her friends are starting to have babies, she is feeling the impact of her infertility strongly." Where conceiving naturally was no longer an option, this appeared to perpetuate survivors' anxieties. In one case, the notes recorded that a patient felt "distressed about discussing adoption and fertility with her husband." Stress also appeared to impact the wider family unit. Notes also recorded that parents of survivors expressed "fear and grief at [survivors'] likely infertility" and concern for their child's overall wellbeing as a result.

The second theme related to survivors' feeling overwhelmed and shocked upon learning about their (potential) infertility. In some cases, it was reported that even the consultation regarding fertility testing was "emotionally traumatic...shocked and overwhelmed upon hearing the news that fertility was compromised." Documentation suggested that the information itself was distressing as it invited thoughts of being unable to have offspring of their own. For others, the notes highlighted that this presented additional challenges in having to communicate with their spouses, particularly as some "haven't openly talked about their desire to start family... resulted in feeling privately stressed and upset about the issue."

The third theme related to avoidance of infertility-related discussions. The documented reasons for this avoidance varied, from being "too embarrassed to discuss fertility" to overall lack of readiness as some simply "did not want to address fertility issues yet." Clinic documentation suggested that the timing of fertility discussions was critical, in some cases resulting in a long-term aversion to the topic. For example, one survivor who "did not wish to discuss it, she feels she was initially told about it at too young an age."

\section{Discussion}

This study reports on a retrospective review of reproductive survivorship care based on a "one-stop shop" pediatric 
oncology model of care. While previous literature has highlighted the reproductive complications of cancer treatment, there is little written on the success of models of reproductive follow-up for pediatric and AYA cancer patients bringing together all aspects of reproductive care. The only adult article detailing a reproductive survivorship model of care reports on a different model of care, which utilizes the role of fertility clinics ${ }^{40}$ rather than their incorporation in the survivorship clinic.

Approaches to FP have changed in recent years to become more proactive. Many survivors currently in survivorship care, especially those treated in earlier periods, did not benefit from the proactive management now followed. Access to this clinic has provided age-appropriate reproductive care delivered by clinicians with a complete understanding of reproductive risks of cancer treatment and information on the patients' complications of cancer treatment, which may have an impact on reproductive advice provided. Patients benefited from a 'one-stop shop model' that allowed them to see a reproductive specialist on the same day they saw the oncologist, endocrinologist, cardiologist, and/or allied health professionals, with patients often having multiple medical appointments on the same day.

Patients who were seen had a wide range of reproductive challenges, and with changing reproductive needs during their survivorship based on expected changes in development and relationship milestones (understanding initial treatment information, pubertal development, establishing sexual relationships and disclosing cancer treatment and complication information, need for contraception advice, planning for future parenthood, and decision to have FP/ART) and then post-family reproductive care. The reproductive needs of patients varied depending on the age of patients.

The reproductive survivorship clinic has provided an opportune time to identify and manage treatment-related reproductive risks and give patients who did not have reproductive discussions or were too young to have these discussions at diagnosis access to reproductive consultations years before family planning begins, giving patients an opportunity to consider FP if missed at diagnosis and if there was a window of opportunity after treatment.

Documented discussion of future pregnancy management was only reported in 5\% of consultations and is an area that can be improved. Many cancer patients and physicians are concerned that pregnancy is not safe in cancer survivors despite available safety data, ${ }^{41-43}$ so our clinic gives patients an opportunity to receive pre-conception assessment and counseling, which is very important for cancer patients. It is also important for cancer patients to have an assessment of the risks that any medical complication of cancer treatment can have on a future pregnancy (hypertension, diabetes, cardiomyopathy, and renal abnormalities), as well as to evaluate the extent of uterine compromise leading to increased incidence of miscarriage, premature delivery, and low birth weight. ${ }^{44-48}$

POI was only recorded in $3.4 \%$ of our female patients, which is lower than published data reporting an incidence of $8 \%-10 \%$ by 40 years of age. ${ }^{24}$ Given that the median age of our population was only 25.0 years, this rate is not only likely to increase as our population ages but also may reflect referral to endocrine specialists outside our service or incomplete documentation. Identification is important so that survivor's symptom burden can be reduced as well as providing management for complications (infertility, bone health, cardiovascular health, and cognitive well-being). ${ }^{22,24}$

Considering $77 \%$ of survivors were predicted to have moderate-to-high risk of infertility, the number of FP procedures reported in this cohort was very low (9\%), but in line with other publications during the time period reviewed. ${ }^{49-53}$ Ovarian cryopreservation is now considered standard of care in pediatric patients and in the future, we will see more prepubertal patients benefiting from this procedure. Despite access to FP services, not every patient will have the opportunities of FP at diagnosis due to disease or symptom burden, time availability, and financial situation, and so rediscussions in the survivorship clinic allow for assessment of reproductive function and decisions about the need of FP post-completion of cancer treatment, if there is a window of opportunity. ${ }^{30,32}$

Documented fertility-related distress in males and females in our study was very low, possibly reflecting access to experienced staff and access to relevant written and verbal reproductive information. However, it may reflect HCPs' and patients' avoidance of discussing these topics ${ }^{1}$ as well as the poor documentation of fertility discussions. ${ }^{54}$ Reproductive late effects are often neglected in discussions, despite patients' strong desires to raise these issues ${ }^{5,56}$ and the documentation of oncofertility care and follow-up has historically been poor. ${ }^{1}$ Patients' knowledge about reproductive risk and care after the completion of cancer treatment (especially for those too young or unwell to be involved in discussions at diagnosis) is often very poor. Details of reproductive health are very personal to patients and patients may not want to disclose or discuss them with the parents. As a result, some clinicians may choose not to record these consultations in notes to maintain confidentiality. Poor documentation limits collaboration between HCPs outside the Survivorship Clinic, who do not receive information about treatment, reproductive risk, and previous FP. ${ }^{54}$

This study showed that despite the availability of support, psychological needs persist over time for some survivors and are not necessarily being met. ${ }^{20}$ Survivors raised concerns about disclosure, impact on current and future relationships, and body image, reflecting literature showing unmet information needs and psychological concerns continue to be reported in patients many years after the completion of cancer treatment. ${ }^{57}$ These can have a significant effect on quality of life and impact on future relationships, family planning, and fertility. ${ }^{58,59}$

This clinic provides an opportunity to provide universal reproductive health advice such as screening for reproductive tumors (self-breast examination, ${ }^{60}$ cervical screening, ${ }^{61}$ and testicular $^{62}$ and prostate screening), ${ }^{63}$ discussion about safe sexual health practices, and contraception, and more recently, HPV vaccination, which have been well described. ${ }^{64}$

\section{Study strengths}

This review is the first study looking at the reproductive services and support provided within a pediatric and adolescent survivorship clinic and reflects a large cohort of pediatric patients followed over a 12-year period. This review provides knowledge that will help us improve our current reproductive model of survivorship care. 


\section{Study limitations}

Despite the researcher's best efforts to extract data, there could be substantial variability among the HCP's providers in terms of what questions were asked and what responses were documented that we are unable to quantify. These differences could exist between providers and even with the same provider on different days. Survivors are also known to be hesitant to bring up reproductive needs, especially as they relate to fertility and sexual health. The use of a self-report questionnaire at each clinic visit or use of a script or template for providers would be needed to uniformly ascertain the reproductive needs and care of cancer patients.

\section{Future directions}

We hope to increase the reach of this service within the Survivorship Clinic to all patients who have an intermediate or high risk of reproductive complications and any patient experiencing reproductive, medical, or psychological symptoms. We intend to develop a reproductive survivorship patient-reported outcome measure that will allow clinicians to identify the medical and psychological reproductive needs of cancer patients and improve the satisfaction that cancer patients have with this clinic.

\section{Conclusions}

Patients who were seen in the survivorship clinic had a wide range of reproductive complications and needs with the reproductive needs of patients varying with the age and gender of patients. The clinic has provided streamlined access to a reproductive specialist and allied health professionals, giving patients an opportunity to have timely reproductive care and support. Targeted screening before the clinic may improve the delivery of reproductive health care, allowing more cancer survivors at risk of reproductive complications to be seen.

\section{Acknowledgment}

We are grateful to all the patients and family members who have attended our reproductive survivorship clinic and all the staff who have provided care to our patients over this time period.

\section{Author Disclosure Statement}

ALL the authors declare that they have no conflicts of interest.

\section{Funding Information}

A.A. position is supported by KCA and CanTeen funding from the Federal Health Department. C.E.W. is supported by a Career Development Fellowship from the National Health and Medical Research Council of Australia (APP1143767).

\section{References}

1. Anazodo A, Ataman-Millhouse L, Jayasinghe Y, Woodruff, TK. Oncofertility-An emerging discipline rather than a special consideration. Pediatr Blood Cancer. 2018; 65(11):e27297.
2. Levine J, Canada A, Stern CJ. Fertility preservation in adolescents and young adults with cancer. J Clin Oncol. 2010;28(32):4831-41.

3. Lass A, Akagbosu F, Brinsden P. Sperm banking and assisted reproduction treatment for couples following cancer treatment of the male partner. Hum Reprod Update. 2001; 7(4):370-7.

4. Denlinger CS, Sanft T, Backer SK, et al. Survivorship, version 2.2017, NCCN clinical practice guidelines in oncology. J Natl Compr Canc Netw. 2017;15(9): 1140-63.

5. Müller J. Disturbance of pubertal development after cancer treatment. Best Pract Res Clin Endocrinol Metab. 2002; 16(1):91-103.

6. Armstrong GT, Chow EJ, Sklar CA. Alterations in pubertal timing following therapy for childhood malignancies, in Endocrinopathy after Childhood Cancer Treatment. Basel: Karger Publishers; 2009; pp. 25-39.

7. Quinn SM, Louis-Jacques J. Menstrual management and reproductive concerns in adolescent and young adult women with underlying hematologic or oncologic disease. Curr Opin Pediatr. 2016;28(4):421-7.

8. Gracia CR, Sammel MD, Freeman E, et al. Impact of cancer therapies on ovarian reserve. Fertil Steril. 2012; 97(1):134-40. e1.

9. Sklar CA, Mertens AC, Mitby P, et al. Premature menopause in survivors of childhood cancer: a report from the childhood cancer survivor study. J Natl Cancer Inst. 2006; 98(13):890-6.

10. Stuenkel CA, Davis SR, Gompel A, et al. Treatment of symptoms of the menopause: an Endocrine Society Clinical Practice Guideline. J Clin Endocrinol Metab. 2015;100(11): 3975-4011.

11. Yoon JY, Park HJ, Ju HY, et al. Gonadal and sexual dysfunction in childhood cancer survivors. Cancer Res Treat. 2017;49(4):1057.

12. Zebrack BJ, Foley S, Wittmann D, et al. Sexual functioning in young adult survivors of childhood cancer. Psychooncology. 2010;19(8):814-22.

13. Chiarelli AM, Marrett LD, Darlington GA. Pregnancy outcomes in females after treatment for childhood cancer. Epidemiology. 2000:161-6.

14. Critchley HO. Factors of importance for implantation and problems after treatment for childhood cancer. Med Pediatr Oncol. 1999;33(1):9-14.

15. Larsen EC, Schmiegelow K, Rechnitzer, et al. Radiotherapy at a young age reduces uterine volume of childhood cancer survivors. Acta Obstet Gynecol Scand. 2004;83(1): 96-102.

16. Reulen RC, Bright CJ, Winter DL, et al. Pregnancy and labor complications in female survivors of childhood cancer: the British Childhood Cancer Survivor Study. J Natl Cancer Inst. 2017;109(11):djx056.

17. Manson JE, Woodruff TK. Reproductive health as a marker of subsequent cardiovascular disease: the role of estrogen. JAMA Cardiol. 2016;1(7):776-7.

18. Popat VB, Callis KA, Vanderhoof VH, et al. Bone mineral density in estrogen-deficient young women. J Clin Endocrinol Metab. 2009;94(7):2277-83.

19. Shuster LT, Rhodes DJ, Gostout BS, et al. Premature menopause or early menopause: long-term health consequences. Maturitas. 2010;65(2):161-6.

20. Logan S, Perz J, Ussher JM, et al. A systematic review of patient oncofertility support needs in reproductive cancer 
patients aged 14 to 45 years of age. Psycho-Oncology. 2018;27(2):401-9.

21. Stinson JN, Jibb LA, Greenberg, et al. A qualitative study of the impact of cancer on romantic relationships, sexual relationships, and fertility: perspectives of Canadian adolescents and parents during and after treatment. J Adolesc Young Adult Oncol. 2015;4(2):84-90.

22. Kenney LB, Antal Z, Ginsberg JP, et al. Improving male reproductive health after childhood, adolescent, and young adult cancer: progress and future directions for survivorship research. J Clin Oncol. 2018;36(21):2160-8.

23. Skinner R, Mulder R, Kremer LC, et al. Recommendations for gonadotoxicity surveillance in male childhood, adolescent, and young adult cancer survivors: a report from the International Late Effects of Childhood Cancer Guideline Harmonization Group in collaboration with the PanCareSurFup Consortium. Lancet Oncol. 2017;18(2):e75-e90.

24. Van Dorp W, Haupt R, Anderson RA, et al. Reproductive function and outcomes in female survivors of childhood, adolescent, and young adult cancer: a review. J Clin Oncol. 2018;36(21):2169-80.

25. Van Dorp W, Mulder RL, Kremer LCM, et al. Recommendations for premature ovarian insufficiency surveillance for female survivors of childhood, adolescent, and young adult cancer: a report from the International Late Effects of Childhood Cancer Guideline Harmonization Group in collaboration with the PanCareSurFup Consortium. J Clin Oncol. 2016;34(28):3440.

26. Benedict C, Thom B, Friedman D, et al. Young adult female cancer survivors' unmet information needs and reproductive concerns contribute to decisional conflict regarding posttreatment fertility preservation. Cancer. 2016;122(13):2101-9.

27. Murphy D, Klosky JL, Reed DR, et al. The importance of assessing priorities of reproductive health concerns among adolescent and young adult patients with cancer. Cancer. 2015;121(15):2529-36.

28. Signorelli C, Wakefield CE, McLoone JK, et al. Models of childhood cancer survivorship care in Australia and New Zealand: strengths and challenges. Asia-Pac J Clin Oncol. 2017;13(6):407-15.

29. Wilson CL, Cohn RJ, Johnston KA, Ashton LJ. Late mortality and second cancers in an Australian cohort of childhood cancer survivors. Med J Australia. 2010;193(5): 258-61.

30. Landier W, Bhatia S, Eshelman DA, et al. Development of risk-based guidelines for pediatric cancer survivors: the Children's Oncology Group long-term follow-up guidelines from the Children's Oncology Group Late Effects Committee and Nursing Discipline. J Clin Oncol. 2004;22(24): 4979-90.

31. Van Dorp W, Van Beek RD, Laven JSE, et al. Long-term endocrine side effects of childhood Hodgkin's lymphoma treatment: a review. Hum Reprod Update. 2012;18(1): $12-28$.

32. Oktay K, Harvey BE, Partridge AH, et al. Fertility preservation in patients with cancer: ASCO clinical practice guideline update. J Clin Oncol. 2018;36(19):1994-2001.

33. Peccatori FA, Azim HA, Orecchia R, et al. Cancer, pregnancy and fertility: ESMO Clinical Practice Guidelines for diagnosis, treatment and follow-up. Ann Oncol. 2013; 24(suppl_6):vi160-70.

34. Meacham LR, Burns K, Orwig KE, Levine J. Standardizing risk assessment for treatment-related gonadal insufficiency and infertility in childhood adolescent and young adult cancer: the pediatric initiative network risk stratification system. J Adolesc Young Adult Oncol. 2020 [Epub ahead of print]; DOI.org/10.1089/jayao.2020.0012.

35. Green DM, Nolan VG, Goodman PJ et al. (2014) The cyclophosphamide equivalent dose as an approach for quantifying alkylating agent exposure: a report from the Childhood Cancer Survivor Study. Pediatr Blood Cancer. 61(1):53-67.

36. Accessed September 2, 2020 from: https://fertilitypreservation pittsburgh.org/fertility-resources/fertility-risk-calculator

37. Zavras N, Siristatidis C, Siatelis A, Koumarianou A. Fertility risk assessment and preservation in male and female prepubertal and adolescent cancer patients. Clinical Medicine Insights: Oncology. 2016;10:CMO-S32811.

38. Neville KA, Cohn RJ, Steinbeck KS, et al. Hyperinsulinemia, impaired glucose tolerance, and diabetes mellitus in survivors of childhood cancer: prevalence and risk factors. J Clin Endocrinol Metab. 2006;91(11):4401-07.

39. Cui L, Qin Y, Gao X, et al. Antimüllerian hormone: correlation with age and androgenic and metabolic factors in women from birth to postmenopause. Fertil Steril. 2016; 105(2):481-5. e1.

40. Massarotti C, Scaruffi P, Lambertini, et al. Beyond fertility preservation: role of the oncofertility unit in the reproductive and gynecological follow-up of young cancer patients. Hum Reprod. 2019;34(8):1462-9.

41. Lambertini M, Di Maio M, Poggio F, et al. Knowledge, attitudes and practice of physicians towards fertility and pregnancy-related issues in youngBRCA-mutated breast cancer patients. Reprod Biomed Online. 2019;38(5): 835-44.

42. Senkus E, Gomez H, Dirix L, et al. Attitudes of young patients with breast cancer toward fertility loss related to adjuvant systemic therapies. EORTC study 10002 BIG 398. Psycho-Oncology. 2014;23(2):173-82.

43. Biglia N, Torrisi R, D'Alonzo M, et al. Attitudes on fertility issues in breast cancer patients: An Italian survey. Gynecol Endocrinol. 2015;31(6):458-64.

44. Critchley HOD, Wallance WHB. Impact of cancer treatment on uterine function. J Natl Cancer Inst Monogr. 2005; 2005(34):64-8.

45. Hartnett KP, Mertens AC, Kramer MR, et al. Pregnancy after cancer: does timing of conception affect infant health? Cancer. 2018;124(22):4401-7.

46. Hartnett KP, Ward KC, Kramer MR, et al. The risk of preterm birth and growth restriction in pregnancy after cancer. Int J Cancer. 2017;141(11):2187-96.

47. Madanat-Harjuoja L-M, Lahteenmaki PM, Dyba T, et al. Stillbirth, early death and neonatal morbidity among offspring of female cancer survivors. Acta Oncol. 2013;52(6): 1152-9.

48. Stensheim H, Klungsoyr K, Skjaeven R, et al. Birth outcomes among offspring of adult cancer survivors: A population-based study. Int J Cancer. 2013;133(11):2696-705.

49. Abe A, Kuwahara A, Iwasa T, et al. A survey on fertility management in young women of reproductive age treated with chemotherapy. Int J Clin Oncol. 2016;21(6):1183-90.

50. Forman EJ, Anders CK, Behera MA, et al. Pilot survey of oncologists regarding treatment-related infertility and fertility preservation in female cancer patients. Int $\mathrm{J}$ Clin Oncol. 2009;54(4):203.

51. Lambertini M, Di Maio M, Poggio F. Physicians' knowledge, attitudes and practice towards fertility and pregnancy- 
related issues in BRCA-mutated breast cancer (BC) patients (pts): Results from the BCY3/BCC 2017 survey. Ann Oncol. 2018;29(suppl_8):mdy300. 009.

52. Mahajan N, Patil M, Kaur S, et al. The role of Indian gynecologists in oncofertility care and counselling. J Hum Reprod Sci. 2016;9(3):179.

53. Rabah DM, Wahdan IH, Merdawy A, et al. Oncologists' knowledge and practice towards sperm cryopreservation in Arabic communities. J Cancer Surviv. 2010;4(3):279-83.

54. Skaczkowski G, White VM, Thompson, et al. Factors influencing the documentation of fertility-related discussions for adolescents and young adults with cancer. Eur $\mathbf{J}$ Oncol Nurs. 2018;34:42-8.

55. Jacobs LA, Pucci D. Adult survivors of childhood cancer: the medical and psychosocial late effects of cancer treatment and the impact on sexual and reproductive health. J Sex Med. 2013;10:120-6.

56. Wang Y, Chen L, Ruan JY, Cheung WY. Discussions about reproductive and sexual health among young adult survivors of cancer. Cancer Med. 2016;5(6):1037-46.

57. Ellis SJ, Wakefield CE, McLoone JK, et al. Fertility concerns among child and adolescent cancer survivors and their parents: a qualitative analysis. J Psychosoc Oncol. 2016;34(5):347-62.

58. Logan S, Perz J, Ussher JM, et al. Systematic review of fertility-related psychological distress in cancer patients: informing on an improved model of care. Psychooncology. 2019;28(1):22-30.

59. Skaczkowski G, White V, Thompson, et al. Factors influencing the provision of fertility counseling and impact on quality of life in adolescents and young adults with cancer. J Psychosoc Oncol. 2018;36(4):484-502.

60. Hassan LM, Mahmoud N, Biller AB, et al. Evaluation of effect of self-examination and physical examination on breast cancer. Breast. 2015;24(4):487-90.

61. Simms KT, Hall M, Smith MA, et al. Optimal management strategies for primary HPV testing for cervical screening: cost-effectiveness evaluation for the National Cervical Screening Program in Australia. PLoS One. 2017;12(1): e0163509.

62. Rovito MJ, Cavayero C, Leone JE, Harlin S. Interventions promoting testicular self-examination (TSE) performance: A systematic review. Am J Men's Health. 2015;9(6): 506-18.

63. Carroll PH, Mohler JL. NCCN Clinical Practice Guidelines in Oncology: Prostate Cancer Early Detection. J Natl Compr Canc Netw. 2018; 16(5S):620-23.

64. St Laurent J, Luckett R, Feldman S. HPV vaccination and the effects on rates of HPV-related cancers. Curr Prob Cancer. 2018;42(5):493-06.

Address correspondence to: Antoinette Catherine Anazodo, MBBS, MSc, PhD

Kids Cancer Centre

Sydney Children's Hospital

Sydney 2031

Australia

E-mail: antoinette.anazodo@health.nsw.gov.au 